\title{
KOMUNIKASI PETUGAS KESEHATAN MEMPENGARUHI PERILAKU IBU HAMIL DALAM MENCEGAH HIPERTENSI
}

\section{COMMUNICATION OF HEALTH OFFICERS AFFECTED PREGNANT WOMEN'S BEHAVIOR IN PREVENTING HYPERTENSION}

\author{
Yusriani $^{*}{ }^{*}$, Muhammad Khidri Alwi ${ }^{2}$, Tutik Agustini ${ }^{3}$ \\ 1,2,3 Fakultas Kesehatan Masyarakat Universitas Muslim Indonesia, Makasar \\ Jl. Urip Sumohardjo Km. 05 Kampus II UMI Makassar Sulsel Indonesia \\ *Email : yusriani.yusriani@umi.ac.id
}

\begin{abstract}
The factor that triggered hypertension during pregnancy is the lack of information obtained by pregnant women about how to prevent hypertension from health workers. The purpose of the study was to determine the effect of health worker communication on the behavior of pregnant women in preventing hypertension. The type of research used is quantitative using a cross-sectional design. The population in the study was 232 pregnant women. Sampling in this study used probability sampling with a simple random sampling technique and the sample size was determined by the Slovin formula of 94 people. Data were collected using a questionnaire then processed and analyzed using the Chi-Square test. The results showed that there were 22 respondents (29.7\%) of pregnant women who had less knowledge and $52(70.3 \%)$ pregnant women who had sufficient knowledge so that there was an effect of communication between health workers and knowledge of pregnant women with p-value (value) $=$ 0.012. There were 26 respondents (35.1\%) of pregnant women who had a negative attitude while those who had a positive attitude were $48(64.9 \%)$ so that there was an effect of communication by health workers on the attitude of pregnant women with a $p$-value (value) $=0.028$. There were 30 respondents $(40.5 \%)$ of pregnant women who had bad actions, while those who had good actions were 44 (59.5\%) so that there was an influence of health worker communication on the actions of pregnant women with a p-value (value) $=0.042$. It is hoped that health workers can improve communication models with pregnant women so that knowledge, attitudes, and actions of pregnant women are more effective.
\end{abstract}

Keywords: Knowledge; attitude; practice; hypertension; a pregnant woman

\begin{abstract}
ABSTRAK
Faktor yang dapat memicu terjadinya hipertensi saat hamil adalah kurangnya informasi yang diperoleh ibu hamil tentang cara pencegahan hipertensi dari petugas kesehatan. Tujuan penelitian yaitu untuk mengetahui pengaruh komunikasi petugas Kesehatan terhadap perilaku ibu hamil dalam mencegah hipertensi. Jenis penelitian yang digunakan adalah kuantitatif menggunakan desain cross sectional. Populasi dalam penelitian sebanyak $232 \mathrm{ibu}$ hamil. Pengambilan sampel dalam penelitian ini menggunakan probability sampling dengan Teknik simple random sampling dan besar sampel ditentukan dengan rumus Slovin sebesar 94 orang. Data dikumpulkan dengan menggunakan kuesioner kemudian diolah dan dianalisis dengan menggunakan uji Chi-Square. Hasil penelitian menunjukkan bahwa didapatkan sebanyak 22 responden $(29.7 \%)$ ibu hamil yang memiliki pengetahuan kurang dan yang memiliki pengetahuan cukup sebanyak 52 (70.3\%), sehingga ada pengaruh komunikasi petugas kesehatan dengan pengetahuan ibu hamil dengan nilai $\mathrm{p}$ (value) $=$ 0,012. Didapatkan sebanyak 26 responden $(35.1 \%)$ ibu hamil yang memiliki sikap negatif sedangkan yang memiliki sikap positif $48(64.9 \%)$ sehingga ada pengaruh komunikasi petugas Kesehatan terhadap sikap ibu hamil dengan nilai p (value) $=0,028$. Didapatkan sebanyak 30 responden $(40.5 \%)$ ibu hamil yang memiliki tindakan kurang baik, sedangkan yang memiliki tindakan baik $44(59.5 \%)$ sehingga ada pengaruh komunikasi petugas kesehatan terhadap tindakan ibu hamil dengan nilai $\mathrm{p} \quad($ value $)=0,042$. Diharapkan kepada petugas Kesehatan agar dapat meningkatkan model komunikasi dengan ibu hamil agar pengetahuan, sikap dan tindakan ibu hamil lebih efektif.
\end{abstract}

Kata Kunci: Pengetahuan; sikap; tindakan; hipertensi; ibu hamil 


\section{PENDAHULUAN}

Hipertensi merupakan penyakit yang berbahaya, terutama apabila terjadi pada wanita yang sedang hamil. Hal ini dapat menyebabkan kematian bagi ibu dan bagi bayi yang akan dilahirkan, Karena tidak ada gejala atau tanda khas sebagai peringatan dini. Hipertensi dalam kehamilan, kejadian ini persentasenya $12 \%$ dari kematian ibu di seluruh dunia yang menyatakan bahwa hipertensi meningkatkan angka kematian dan kesakitan pada ibu hamil (1). Hipertensi berada pada persentase kedua penyebab kematian ibu yaitu (24\%), kejang bisa terjadi pada pasien dengan tekanan darah tinggi (hipertensi) yang tidak terkontrol saat persalinan. Hipertensi dapat terjadi karena kehamilan dan akan kembali normal bila kehamilan sudah berakhir. Namun ada juga yang tidak kembali normal setelah bayi lahir. Kondisi ini akan menjadi lebih berat bila hipertensi sudah diderita ibu sebelum masa kehamilan (2).

Data situasi kesehatan ibu menggambarkan angka kematian ibu karena hipertensi dalam kehamilan pada tahun 2016 sebesar 21,5\% dan pada tahun 2017 menjadi 27,1\% menunjukan terjadi peningkatan sebesar 5,6\% (3). Berdasarkan profil kesehatan provinsi Sulawesi Selatan tahun 2015 prevalensi hipertensi pada perempuan $47,73 \%$ lebih besar dibandingkan dengan laki-laki 38,51\%. Hipertensi lebih sering menyerang perempuan dikarenakan berbagai macam faktor pendukung, terutama pada perempuan yang mengalami kehamilan karena masa kehamilan yang rentan dimana selama kehamilan dan dapat menimbulkan komplikasi pada 2-3\% kehamilan (4). Data dari dinas kesehatan Kabupaten Luwu Utara pada tahun 2019 ditemukan 5656 ibu hamil dengan usia 15-39 tahun dan diperoleh angka ibu hamil beresiko terjadi hipertensi sebanyak 739 ibu hamil. Berdasarkan data di puskesmas Tanalili Kabupaten Luwu Utara pada bulan desember 2019 terdapat 4 orang ibu hamil yang disebabkan karena hipertensi (preeklampsiaeklampsia) sedangkan pada bulan Januari 2020 terdapat 7 orang ibu hamil yang disebabkan karena hipertensi (Preeklampsia-Eklampsia) (5).

Hal ini menunjukkan bahwa ibu hamil dengan risiko tinggi yang disebabkan oleh hipertensi (Preeklampsia Eklampsia) semakin hari semakin bertambah, tingginya kejadian hipertensi dalam kehamilan mempunyai kaitan erat dengan angka kesakitan dan kematian janin. Salah satu cara untuk menanggulangi masalah kesehatan adalah dengan pencegahan terjadinya hipertensi bagi masyarakat secara umum khususnya pada ibu hamil. Pencegahan hipertensi perlu dilakukan oleh semua penderita hipertensi agar tidak terjadi peningkatan tekanan darah yang lebih parah. Tetapi sayangnya tidak semua penderita hipertensi dapat melakukan pencegahan terhadap penyakitnya. Hal ini disebabkan karena tingkat pengetahuan penderita hipertensi tentang pencegahan hipertensi masih sangat kurang dikarenakan salah satu faktor yang mempengaruhi pengetahuan terhadap kesehatan adalah tingkat pendidikan. pendidikan merupakan hal yang sangat penting dalam mempengaruhi pikiran seseorang. Orang yang berpendidikan akan mampu berfikir tenang terhadap suatu masalah termasuk dalam pengetahuan tentang hipertensi $(6,7)$. Faktor lain yang dapat memicu terjadinya hipertensi saat hamil adalah kurangnya informasi yang diperoleh ibu hamil tentang pendidikan kesehatan ibu hamil, disinilah peran komunikasi kesehatan bidan desa dibutuhkan. Bidan desa dituntut untuk aktif memberikan pelayanan, pencegahan, hingga penyuluhan kepada masyarakat akan pentingnya menjaga kesehatan. Disinilah komunikasi kesehatan berperan. Komunikasi kesehatan yang didefinisikan sebagai modifikasi perilaku manusia serta factor-faktor sosial yang berkaitan dengan perilaku yang secara langsung dan tidak langsung mempromosikan kesehatan, mencegah penyakit atau melindungi individuindividu terhadap bahaya. Karena berakar pada bidang pendidikan dan penyuluhan kesehatan, maka komunikasi kesehatan sangat dipengaruhi oleh psikologi, komunikasi dan berbagai disiplin ilmu perilaku yang lain $(8,9)$. Penyuluhan yang dilakukan bertujuan untuk meningkatkan pengetahuan kesehatan sekaligus meningkatkan kesadaran masyarakat akan pentingnya menjaga kesehatan. Hal ini sesuai penelitian sebelumnya bahwa pasien hipertensi dengan tingkat kesadaran yang rendah harus diberikan pendidikan dan intervensi yang efektif seperti bimbingan langsung. Hal ini akan mampu memperbaiki manajemen kesehatan di masyarakat dan manajemen diri penderita hipertensi yang buruk (10). 
Berdasarkan uraian sebelumnya, maka tujuan penelitian adalah untuk mengetahui pengaruh komunikasi petugas Kesehatan terhadap perilaku ibu hamil dalam mencegah hipertensi.

\section{BAHAN DAN METODE}

Jenis penelitian yang digunakan adalah penelitian kuantitatif. Desain penelitian yang digunakan yaitu cross sectional. Populasi dalam penelitian ini adalah ibu hamil yang bertempat di wilayah kerja Puskesmas Tanalili, Kecamatan Tanalili, Kabupaten Luwu Utara sebanyak 232 ibu hamil. Sampel dalam penelitian ini adalah ibu hamil yang bertempat di wilayah kerja Puskesmas Tanalili, Kecamatan Tanalili, Kabupaten Luwu Utara. Besar sampel pada penelitian ini menggunakan rumus Slovin yang berjumlah 94 orang ibu hamil. Pengambilan sampel dalam penelitian ini menggunakan probability sampling dengan Teknik simple random sampling. Variabel yang diukur adalah pengetahuan, sikap, tindakan dan komunikasi petugas Kesehatan. Pengumpulan data pada penelitian ini menggunakan kuesioner dimana peneliti akan bertemu dengan responden dan respondenlah yang mengisi daftar pertanyaan tersebut. Analisis data yang dilakukan untuk mengetahui pengaruh masing-masing variabel independen dengan variabel dependen dengan menggunakan uji Chi Square.

\section{HASIL DAN PEMBAHASAN}

\section{Analisis Univariat}

Tabel 1. Karakteristik Responden

\begin{tabular}{lcc}
\hline \multicolumn{1}{c}{ Variabel } & $\mathrm{f}$ & $\%$ \\
\hline Kelompok Umur & & \\
$20-35$ tahun & 83 & 88,6 \\
$>35$ tahun & 11 & 11,4 \\
Pendidikan & & \\
Tidak Tamat SD & 10 & 10,6 \\
SD & 18 & 19,1 \\
SMP & 18 & 19,1 \\
SMA & 26 & 27.6 \\
Perguruan Tinggi & 12 & 12.6 \\
Pekerjaan & & \\
Ibu Rumah Tangga & 73 & 77,6 \\
PNS & 17 & 18,0 \\
Buruh Harian & 4 & 4,4
\end{tabular}

\section{Kehamilan}

$1 \quad 30 \quad 31,9$

$\begin{array}{lll}2-3 & 51 & 54,2\end{array}$

$\begin{array}{lll}>3 & 13 & 13,9\end{array}$

Umur Kehamilan

1-3 Bulan $25 \quad 26,6$

4-6 Bulan $\quad 30 \quad 31,9$

7-9 Bulan $39 \quad 41,5$

Kriteria Tekanan Darah

Hipertensi $\quad 22 \quad 23,4$

$\begin{array}{lll}\text { Normal } & 68 & 72,2\end{array}$

$\begin{array}{lll}\text { Hipotensi } & 7 & 57,4\end{array}$

Jarak Kehamilan

$\begin{array}{lll}<2 & 12 & 12,7\end{array}$

$\begin{array}{lll}\geq 2 & 62 & 65,9\end{array}$

Kehamilan Pertama $\quad 20 \quad 21,4$

LILA

$\begin{array}{lll}<23.5 & 11 & 11,7\end{array}$

$\geq 23,5 \quad 83 \quad 88,3$

Riwayat Hipertensi

$\begin{array}{lll}\text { Tidak } & 82 & 87,3\end{array}$

$\begin{array}{lll}\text { Ya } & 12 & 12,7\end{array}$

Keluarga Yang Hipertensi

$\begin{array}{lll}\text { Tidak } & 79 & 84,0\end{array}$

Ya $15 \quad 16,0$

$\begin{array}{lll}\text { Total } & 94 & 100,0\end{array}$

Tabel 1 menunjukkan bahwa mayoritas ibu hamil memiliki umur 20-35 tahun (88,6\%), tingkat pendidikan SMA $(27,6 \%)$, bekerja sebagai ibu rumah tangga (77,6\%), memiliki frekuensi kehamilan ke 2-3 (54,2\%), memiliki umur kehamilan 7-9 bulan (41,5\%), ibu hamil yang menderita hipertensi $(23,4 \%)$, jarak kehamilan $<2$ tahun (12,7\%). Lingkar lengan atas $<23,5 \mathrm{~cm}(11,7 \%)$, ibu hamil yang memiliki riwayat hipertensi $(12,7 \%)$ dan memiliki keluarga menderita hipertensi (16\%). 


\section{Analisis Bivariat}

Tabel 2. Pengaruh Komunikasi Petugas dengan Pengetahuan Ibu Hamil Dalam Mencegah Hipertensi Di Wilayah Kerja Puskesmas Tanalili Tahun 2020

\begin{tabular}{|c|c|c|c|c|c|c|c|}
\hline \multirow{3}{*}{$\begin{array}{c}\text { Komunikasi } \\
\text { Petugas Kesehatan }\end{array}$} & \multicolumn{4}{|c|}{ Pengetahuan } & \multirow{2}{*}{\multicolumn{2}{|c|}{ Total }} & \multirow{3}{*}{$\rho$ - Value } \\
\hline & \multicolumn{2}{|c|}{ Kurang } & \multicolumn{2}{|c|}{ Cukup } & & & \\
\hline & $\mathrm{n}$ & $\%$ & $\mathrm{n}$ & $\%$ & $\mathrm{n}$ & $\%$ & \\
\hline Kurang Efektif & 18 & 40,9 & 26 & 59,1 & 44 & 100,0 & \multirow{3}{*}{0,012} \\
\hline Efektif & 14 & 28,0 & 36 & 72,0 & 50 & 100,0 & \\
\hline Total & 32 & 34,0 & 62 & 65,0 & 94 & 100,0 & \\
\hline
\end{tabular}

Tabel 2 menunjukkan bahwa didapatkan sebanyak 18 responden (40,9\%) ibu hamil yang memiliki pengetahuan kurang dengan komunikasi petugas kesehatan kurang efektif, sedangkan yang memiliki pengetahuan cukup 36 (72\%) dengan komunikasi petugas kesehatan efektif. Berdasarkan hasil analisis statistik uji Chi-Square diperoleh nilai $p$ (value) =0,012 dengan demikian ada pengaruh komunikasi petugas kesehatan terhadap pengetahuan ibu hamil di Puskesmas Tanalili.

Tabel 3. Pengaruh Komunikasi Petugas dengan Sikap Ibu Hamil Dalam Mencegah Hipertensi Di Wilayah Kerja Puskesmas Tanalili Tahun 2020

\begin{tabular}{|c|c|c|c|c|c|c|c|}
\hline \multirow{3}{*}{$\begin{array}{c}\text { Komunikasi } \\
\text { Petugas Kesehatan }\end{array}$} & \multicolumn{4}{|c|}{ Sikap } & \multirow{2}{*}{\multicolumn{2}{|c|}{ Total }} & \multirow{3}{*}{$\rho$ - Value } \\
\hline & \multicolumn{2}{|c|}{ Negatif } & \multicolumn{2}{|c|}{ Positif } & & & \\
\hline & $\mathrm{n}$ & $\%$ & $\mathrm{n}$ & $\%$ & $\mathrm{n}$ & $\%$ & \\
\hline Kurang Efektif & 21 & 47,7 & 23 & 52,3 & 44 & 100,0 & \multirow{3}{*}{0,028} \\
\hline Efektif & 15 & 30,0 & 35 & 70,0 & 50 & 100,0 & \\
\hline Total & 36 & 38,2 & 58 & 61,8 & 94 & 100,0 & \\
\hline
\end{tabular}

Tabel 3 menunjukkan bahwa didapatkan sebanyak 21 responden (47,7\%) ibu hamil yang memiliki sikap negatif dengan komunikasi petugas kesehatan kurang efektif, sedangkan yang memiliki sikap positif 35 (70\%) dengan komunikasi petugas kesehatan efektif. Berdasarkan hasil analisis statistik uji Chi-Square diperoleh nilai $\mathrm{p}$ (value) = 0,028 dengan demikian ada pengaruh komunikasi petugas kesehatan terhadap sikap ibu hamil di Puskesmas Tanalili.

Tabel 4. Pengaruh Komunikasi Petugas dengan Tindakan Ibu Hamil Dalam Mencegah Hipertensi Di Wilayah Kerja Puskesmas Tanalili Tahun 2020

\begin{tabular}{|c|c|c|c|c|c|c|c|}
\hline \multirow{3}{*}{$\begin{array}{c}\text { Komunikasi } \\
\text { Petugas Kesehatan }\end{array}$} & \multicolumn{4}{|c|}{ Tindakan } & \multirow{2}{*}{\multicolumn{2}{|c|}{ Total }} & \multirow{3}{*}{$\rho$ - Value } \\
\hline & \multicolumn{2}{|c|}{ Kurang } & \multicolumn{2}{|c|}{ Cukup } & & & \\
\hline & $\mathrm{n}$ & $\%$ & $\mathrm{n}$ & $\%$ & $\mathrm{n}$ & $\%$ & \\
\hline Kurang Efektif & 22 & 50,0 & 22 & 50,0 & 44 & 100,0 & \multirow{3}{*}{0,042} \\
\hline Efektif & 18 & 36,0 & 32 & 64,0 & 50 & 100,0 & \\
\hline Total & 40 & 42,6 & 54 & 57,4 & 94 & 100,0 & \\
\hline
\end{tabular}

Tabel 4 menunjukkan bahwa didapatkan sebanyak 22 responden (50\%) ibu hamil yang memiliki tindakan kurang baik dengan komunikasi petugas kesehatan kurang efektif, sedangkan yang memiliki tindakan cukup baik 32 (64\%) dengan komunikasi petugas kesehatan efektif. Berdasarkan hasil analisis statistik uji Chi-Square diperoleh nilai p (value) = 0,042 dengan demikian ada pengaruh komunikasi petugas kesehatan terhadap tindakan ibu hamil di Puskesmas Tanalili.

\section{PEMBAHASAN}

Pengaruh komunikasi petugas kesehatan dengan perilaku ibu hamil dalam mencegah hipertensi di puskesmas tanalili tahun 2020, maka penulis akan memapakarkan hasil satu persatu yang telah diperoleh. Sampel dalam penelitian ini berjumlah 94 orang ibu hamil diambil dari berbagai Desa yang ada di Wilayah kerja puskesmas Tanalili. 
Penelitian ini di lakukan dengan cara membagian kuesioner kepada ibu hamil yang berkunjung di puskesmas dan pustu sebagai pengukuran pengaruh komunikasi petugas kesehatan terhadap perilaku ibu hamil dalam mencegah hipertensi. Pada tabel 2 menunjukkan ada pengaruh komunikasi petugas kesehatan terhadap pengetahuan ibu hamil, Menurut Notoatmodjo (2012), pengetahuan merupakan hasil dari tahu dan ini terjadi setelah orang melakukan penginderaan terhadap suatu objek tertentu. Kemampuan mengingat, memahami, menerapkan, menganalisis, mengevaluasi/menilai dan mencipta dapat menjadi faktor terbentuknya pengetahuan yang baik (11).

Proses pemberian komunikasi petugas kesehatan terhadap ibu hamil yang sesuai standar diharapkan berjalan baik, di mana petugas Kesehatan menyampaikan informasi mengenai hipertensi dengan benar yang dapat memberikan pengaruh untuk ibu hamil, baik untuk pengetahuan ibu hamil maupun perilaku ibu hamil dalam mencegah hipertensi. Komunikasi dapat menambah informasi yang diperoleh ibu hamil sehingga ibu hamil bisa memiliki kesadaran untuk memilihara kesehatan terutama pada masalah pencegahan terjadinya hipertensi. Pengetahuan dilihat dari sampai dimana ibu hamil mampu mengingat, memahami dan menerapkan. Hasil penelitian didapatkan bahwa pengaruh komunikasi petugas kesehatan terhadap pengetahuan ibu hamil, dapat dilihat dari beberapa jawaban pertanyaan ibu hamil tentang pengetahuan cukup didapatkan sebanyak 62 (65\%) ibu hamil, dimana ibu hamil sudah memiliki kemampuan dalam mengingat informasi terkait penderita hipertensi tidak boleh mengkonsumsi garam yang berlebihan, mengkonsumsi makanan tinggi lemak dapat menimbulkan kekambuhan pada penyakit hipertensi, penderita hipertensi harus melakukan olahraga yang teratur, serta ibu hamil mengetahui nilai normal tekanan darah, sehingga kemampuan memahami terkait perilaku ibu hamil dalam mencegah hipertensi sudah cukup baik, hal ini disebabkan karena ibu hamil cukup mendapatkan informasi dari berbagai sumber, baik media cetak, elektronik, maupun dari petugas kesehatan.

Hasil penelitian menunjukkan bahwa diharapkan kepada petugas kesehatan dapat terus mempertahankan komunikasi yang baik antara petugas kesehatan dengan ibu hamil terkhusus pemberian informasi melalui media sebagai wujud nyata yang mampu menambah pengetahuan ibu hamil, dan memberikan pelayanan yang berkualitas sehingga ibu hamil tetap menjaga kesehatan, dan mengurangi terjadinya kejadian hipertensi pada ibu hamil. Pengetahuan adalah sesuatu yang diperoleh dari pengalaman yang berasal dari berbagai macam sumber seperti, media poster, kerabat dekat, media massa, media elektronik, buku petunjuk, petugas kesehatan, dan sebagainya. Pengetahuan dapat membentuk keyakinan tertentu, sehingga seseorang berperilaku sesuai dengan keyakinannya tersebut (12). Hasil penelitian ini sejalan dengan penelitian sebelumnya tentang hubungan pengetahuan Ibu tentang hipertensi dalam kehamilan di RSB Kasih Bunda, diperoleh hasil bahwa terdapat hubungan yang signifikan antara pengetahuan dengan hipertensi dalam kehamilan, dengan P-Value $=0,003$ dan $\mathrm{OR}=2,34.8,9,10$ (13).

Pada tabel 2 menunjukkan ada pengaruh komunikasi petugas kesehatan terhadap sikap ibu hamil, Menurut Notoatmodjo (2003) bahwa Sikap merupakan reaksi atau respon yang masih tertutup dari seseorang terhadap suatu stimulus atau objek, yang secara nyata menunjukkan konotasi adanya kesesuaian reaksi terhadap stimulus tertentu yang dalam kehidupan sehari-hari merupakan reaksi yang bersifat emosional terhadap stimulus sosial. Sikap positif dilihat dari kemampuan penerimaan, responsif, nilai diri, organisasi dan karakterisasi $(14,15)$. Berdasarkan pernyatan sikap ibu hamil dalam mencegah hipertensi diperoleh bahwa sebanyak 58 (61,8\%) ibu hamil bersikap positif. Dapat dilihat dari beberapa pernyataan terkait Jika ibu hamil merasa pusing dan tengkuk terasa berat dalam jangka waktu yang lama sebaiknya memeriksakan diri ke pelayanan kesehatan terdekat, Ibu hamil 
penderita hipertensi sebaiknya memeriksakan tekanan darah secara teratur tiap bulan dan mengontrol pola makan serta beberapa pernyataan lainnya yang sudah baik sehingga membuat sikap ibu hamil menjadi positif. Berdasarkan hasil penelitian terdapat sebagian memiliki sikap yang positif terhadap perilaku ibu hamil dalam mencegah hipertensi. Hal ini dapat disebabkan karena memilik pengetahuan yang cukup sehingga akan terbentuk sikap yang positif. Dari hasil penelitian didapatkan bahwa sikap terhadap perilaku ibu hamil dalam mencegah hipertensi merupakan salah satu faktor yang mempengaruhi hipertensi dalam kehamilan di Puskesmas Tanalili Luwu Utara. Hal ini disebabkan karena sikap menunjukkan bagaimana perilaku atau kecenderungan berperilaku dengan yang ada dalam diri seseorang, dengan sikap yang positif terhadap perilaku ibu hamil dalam mencegah hipertensi, ibu hamil akan cenderung berperilaku positif dalam mencegah terjadinya hipertensi. Hal ini dibuktikan dari hasil penelitian ini yang menunjukan bahwa ada hubungan antara sikap ibu hamil dengan perilaku ibu hamil dalam mencegah hipertensi.

Komunikasi petugas Kesehatan yang efektif sangat mempengaruhi bagaimana sikap ibu hamil menanggapi terkait informasi tentang hipertensi. Sikap positif terbentuk karena komunikasi petugas kesehatan yang efektif yang disebabkan karna keterbukaan petugas kesehatan dalam memberikan pengaruh yang baik kepada ibu hamil dengan melakukan tindakan kecil seperti perkenalan diri, serta informasi yang mudah dan mampu di pahami dengan dukungan media sebagai saluran penambah pengetahuan $(16,17)$. Pada penelitian ini diharapkan petugas kesehatan mampu meningkatkan dan mempertahankan memberikan informasi yang baik terkait hipertensi kepada ibu hamil sehingga mampu mempengaruhi ibu hamil untuk melakukan kepatuhan baik dalam mengontrol pola makan, maupun pencegahan lainnya dalam mengatasi hipertensi. Sehingga mampu meningkatkan pengetahuan sebagai peranan penting dalam pembentukan sikap ibu terhadap pentingnya mencegah terjadinya hipertensi pada masa kehamilan dipengaruhi oleh pengetahuan yang dimilikinya. Hasil penelitian ini sejalan dengan hasil penelitian yang menunjukkan bahwa nilai significancy $0,013(\mathrm{p}<0,05)$ yang dapat diartikan ada pengaruh sikap ibu tentang TTD yang bermakna antara kelompok intervensi yang diberikan edukasi konseling menggunkan media leaflet dan kelompok control yang tidak mendapatkan perlakuan (18). Hasil penelitian menunjukkan 51,8\% subjek memiliki sikap yang baik. Pada penelitian ini ditemukan faktor yang mendasar terbentuknya sikap diantaranya pengetahuan, pengalaman pribadi, dan orang lain yang dianggap penting seperti petugas Kesehatan (19). Terdapat 3 komponen pokok yang memegang peran penting dalam menentukan sikap seseorang yaitu kepercayaan atau keyakinan, kehidupan emosional dan kecenderungan untuk bertindak. Sikap (attitude) adalah istilah yang mencerminkan rasa senang, tidak senang atau perasaan biasa-biasa saja (netral) dari seseorang terhadap benda, kejadian, situasi orang-orang atau kelompok. Kalau yang timbul terhadap sesuatu itu adalah perasaan senang/tertarik akan disebut sikap positif, sedangkan kalau yang timbul itu perasaan tidak senang disebut sikap negatif $(20,21)$.

Pada tabel 3 menunjukkan bahwa ada pengaruh komunikasi petugas kesehatan terhadap tindakan ibu hamil, tindakan merupakan upaya untuk mewujudkan sikap menjadi suatu perbuatan nyata yang memerlukan faktor pendukung atau kondisi yang memungkinkan. Menurut Green (1990), ada beberapa faktor yang mempengaruhi tindakan, yaitu ketersediaan fasilitas kesehatan (22). Dengan adanya fasilitas kesehatan dapat mendukung seseorang untuk melakukan sesuatu dalam hal menjaga kesehatan. Faktor selanjutnya yaitu pengetahuan dan sikap ibu hamil. Dengan adanya pengethuan yang baik disertai sikap yang baik pula, maka akan memberikan pengaruh untuk melakukan tindakan baik pula $(23,24)$.

Pengetahuan dan sikap sangat erat kaitannya dengan tindakan yang dimiliki seseorang. 
Pengetahuan dan sikap yang semakin baik maka tindakan tersebut juga akan baik dan apabila seorang ibu dapat bertindak baik saat mencegah hipertensi dalam kehamilan, maka ibu hamil juga terhindar dari hipertensi. Dilihat dari hasil penelitian ini dimana petugas kesehatan dalam hal ini bidan sangat efektif dalam meyampaikan informasi sehingga dapat menyebabkan tindakan baik, dapat dilihat dari tindakan baik ibu hamil didapati sebanyak 54 (57,4\%) ibu hamil, hal ini karena ibu hamil tidak merokok, rajin memeriksa kehamilan, hal ini bisa dikatakan komunikasi petugas kesehatan dengan ibu hamil terbilang baik dan tindakan ibu hamil juga cukup baik. Dengan demikian hasilnya adalah bermakna, yang berarti ada pengaruh komunikasi petugas kesehatan terhadap tindakan ibu hamil di Puskesmas Tanalili.

Hasil observasi bahwa semakin tinggi pengetahuan ibu hamil yang dimiliki semakin tinggi pula dukungan sikap positif yang dilakukan sehingga hal tersebut mampu mewujudkan sebuah hasil dalam bentuk tindakan baik yang dilakukan ibu hamil dalam mencegah hipertensi, hal tersebut juga di dukung dengan komunikasi efektif dari petugas kesehatan dalam hal ini bidan dimana salah satu faktor yang dapat mempengaruhi tindakan adalah peran tenaga kesehatan untuk meningkatkan motivasi dan dukungan terhadap ibu hamil. Tenaga kesehatan juga perlu mempertahankan serta meningkatkan penyampaian informasi baik dengan menggunakan media ataupun penyuluhan yang dilakukan secara terus menerus sehingga ibu hamil paham dan mampu melakukan tindakan dalam pencegahan hipertensi $(25,26)$. Dengan hal tersebut ibu hamil mampu menciptakan tindakan yang jauh lebih baik kedepannya. Hasil penelitian ini sejalan dengan penelitian yang disimpulkan bahwa ada hubungan yang bermakna antara peran petugas kesehatan terhadap kepatuhan ibu hamil $(25,27)$.

\section{KESIMPULAN DAN SARAN}

Ada pengaruh komunikasi petugas kesehatan terhadap pengetahuan ibu hamil $(\mathrm{p}=0,012)$, ada pengaruh komunikasi petugas kesehatan terhadap sikap ibu hamil $(p=0.028)$, dan ada pengaruh komunikasi petugas kesehatan terhadap tindakan ibu hamil $(p=0,042)$ dalam mencegah hipertensi di Puskesmas Tanalili tahun 2020. Petugas kesehatan harus mampu meningkatkan model komunikasi yang sifatnya dua arah dengan ibu hamil, menggunakan metode dan media yang efektif agar pengetahuan, sikap dan tindakan ibu hamil semakin baik. Perlu melakukan penelitian lanjutan tentang pemberian intervensi kepada petugas Kesehatan dalam meningkatkan skill komunikasi sehingga berdampak pada perilaku ibu hamil.

\section{UCAPAN TERIMAKASIH}

Terima kasih Kepada Lembaga Penelitian dan Pengembangan Sumber Daya Universitas Muslim Indonesia (LP2S UMI) atas bantuan pendanaan riset dan publikasi pada skim penelitian internal, seluruh responden penelitian dan pemerintah khususnya Puskesmas Tanalili, Kecamatan Tanalili, Kabupaten Luwu Utara.

\section{DAFTAR PUSTAKA}

1. Kemenkes RI. Kejadian Hipertensi dalam Kehamilan di Indonesia. Jakarta: Kemenkes RI. 2015.

2. SDKI. Penyebab Kematian Ibu di Indonesia. Jakarta: Survei Demografi Dan Kesehatan Indonesia. 2017.

3. Kemenkes RI. Hipertensi. Infodatin Pusat Data dan Informasi Kementrian kesehatan RI. 2017; (Hipertensi):1-7.

4. Profil Kesehatan Provinsi Sulsel. Data Hipertensi Penduduk Menurut Jenis Kelamin, Kecamatan Dan Puskesmas Provinsi Sulsel. 2015.

5. Dinkes Luwu Utara. Profil Kesehatan Kabupaten Luwu Utara. Masamba: Dinas Kesehatan. 2019

6. Sasmita, Fatima Nuraini, Dian Dwiana, and Getha Parera. Hubungan Perilaku Asertif Perawat Dalam Memberikan Pelayanan Keperawatan Dengan Tingkat Kepuasan Pasien Di Ruang Seruni RSUD DR. M. Yunus Bengkulu. PREPOTIF: Jurnal Kesehatan Masyarakat 4.2 (2020): 121-130

7. Angkawijaya, Arsenius Agung, Pangemanan, Jane M, Siagian, Iyone ET. Hubungan tingkat pengetahuan masyarakat dengan tindakan 
pencegahan hipertensi di Desa Motoboi Kecil Kecamatan Kotamobagu Selatan. Jurnal Kedokteran Komunitas dan Tropik, 2016, 4(1)

8. Mulyati, Lia, Yetti, Krisna, Sukmarini, Lestari. Analisis faktor yang memengaruhi self management behaviour pada pasien hipertensi. Jurnal keperawatan padjadjaran, 2013, 1(2)

9. Angraini, Dian Isti, et al. Penerapan eKIE (Komunikasi, Informasi, dan Edukasi Elektronik) Dalam Upaya Meningkatkan Kemampuan Perawatan Diri Penderita Hipertensi Pada Masa Pandemik COVID-19. In: Seminar Nasional ADPI Mengabdi Untuk Negeri. 2021.51); 237-242.

10. Wang, C., Lang, J., Xuan, L., Li, X., \& Zhang, L. The Effect of Health Literacy and Selfmanagement Efficacy on The Health-related Quality of Life Of Hypertensive Patients in A Western Rural Area of China: A Cross Sectional Study. International Journal for Equity in Health. 2017

11. Notoatmodjo, S. Pendidikan dan Perilaku Kesehata. Jakarta : Rineka Cipta. 2003

12. Istiari. Ilmu Pengetahuan Tentang Kehamilan. Salemba Medika: Jakarta. 2012

13. Putri,Anita. Hubungan Pengetahuan dan Sikap Terhadap Hipertensi dalam Kehamilan. RSB Kasih Bunda. 2010.

14. Yusriani Y, Alwi MK. Buku ajar promosi kesehatan dan pemberdayaan masyarakat. Book \& Articles Of Forikes. 2018 Mar 31;9:1-59.

15. Notoatmodjo S. Promosi Kesehatan dan Perilaku Kesehatan. Jakarta: PT Rineka Cipta. 2012

16. Dewi S, Romalita Y, Yusriani Y, Alwi MK. Perceptions of pregnant woman on monetary and time sacrifice for satisfaction based on health workers roles in antenatal services to reduce the risk of maternal death at Gowa district. Heal Sci J Indones. 2019;10(2):111-8.

17. Yusriani, Muhammad Khidri Alwi, Yuni Romalita SD. The Role of Public Health Workers As a Facilitator In Preventing of Maternal Death In Gowa District. 2018;1:86-90.

18. Harijanto $W$, Rudijanto A. Pengaruh konseling motivational interviewing terhadap kepatuhan minum obat penderita hipertensi. Jurnal Kedokteran Brawijaya. 2015 Jul 8;28(4):354-3.
19. Hermawan NS, Zakaria D, Umar MY. Efektivitas Konseling Pasien Hipertensi Terhadap Perilaku Kepatuhan Berobat. ARKESMAS (Arsip Kesehatan Masyarakat). 2020 Jun 30;5(1):49-52.

20. Dewanti SW, Andrajati R, Supardi S. Pengaruh konseling dan leaflet terhadap efikasi diri, kepatuhan minum obat, dan tekanan darah pasien hipertensi di Dua Puskesmas Kota Depok. Jurnal Kefarmasian Indonesia. 2015 Feb 17:33-40.

21. Luthfi, Ikhwan, 2009. "Psikologi Sosial". Jakarta : Lembaga Penelitian UIN Jakarta. Hal. 1.

22. Green, Lawrence. Health Education: A Diagnosis Approach, The John Hopkins University, Mayfield Publishing Co. 1990

23. Yusriani. Implementasi Pelayanan Kesehatan di Wilayah Kerja Puskesmas Bontomate'ne, Kecamatan Turatea, Kabupaten Jeneponto. 2018; (1):78-83.

24. Dewanti SW, Andrajati R, Supardi S. Pengaruh konseling dan leaflet terhadap efikasi diri, kepatuhan minum obat, dan tekanan darah pasien hipertensi di Dua Puskesmas Kota Depok. Jurnal Kefarmasian Indonesia. 2015 Feb 17:33-40.

25. Aprilia S, Yusriani Y, Ikhtiar M. Model Komunikasi SMCR Bidan Berhubungan dengan Pengetahuan Ibu Hamil dalam Mencegah Kematian Ibu. WoPHJ [Internet]. 2021May26 [cited 2021Oct.25];1(6):808-14. Available from: http://jurnal.fkm.umi.ac.id/index.php/woph/ article/view/198

26. Suryani S, Rahmawati R. Efektivitas Konseling Keluarga Terhadap Peningkatan Kualitas Hidup Pasien Hipertensi. The Shine Cahaya Dunia D-Iii Keperawatan. 2018 Apr 20;3(1).

27. Herlina $H$, Yusriani $Y$, Idris FP. Pendekatan Health Belief Model Dalam Komunikasi Interpersonal Tentang Protokol Kesehatan Antara Ibu Hamil dan Petugas Kesehatan: Health Belief Model Approach in Interpersonal Communication About Health Protocols Between Pregnant Women and Health Workers. JMCH [Internet]. 2021Oct.13 [cited 2021Oct.25];2(4):4155. Available from: http://pascaumi.ac.id/index.php/imch/article/view/695 